\title{
Synergistic coupling of NiFeZn-OH nanosheet network arrays on a hierarchical porous NiZn/Ni heterostructure for highly efficient water splitting
}

\author{
Qiuxia Zhou ${ }^{1}$, Caixia $\mathrm{Xu}^{1 *}$, Yaxin $\mathrm{Li}^{1}$, Ximiao Xie ${ }^{1}$, Hong Liu ${ }^{1,2^{*}}$ and Shishen $\mathrm{Yan}^{1^{*}}$
}

\begin{abstract}
Efficient and economical electrocatalysts should be developed for oxygen evolution reaction (OER) and hydrogen evolution reaction (HER) to split water for an extensive application prospect of green and clean hydrogen energy. Here, we develop highly efficient OER and HER electrocatalysts through the scalable fabrication of NiFeZn hydroxide nanosheets firmly arrayed on a hierarchical porous intermetallic NiZn and Ni heterojunction over nickel foam (NiFeZn-OH/NiZn-Ni/NF). One bimodal porous NiZn intermetallic/Ni layer is in situ constructed on the nickel foam surface to maximize the exposure of catalytic sites and build firm $\mathrm{NiFeZn-OH}$ nanosheets via the redox reaction with $\mathrm{FeCl}_{3}$. NiFeZn-OH/NiZn-Ni/NF shows low overpotentials of $\boldsymbol{y}_{50 / 600}$ around $235 / 284 \mathrm{mV}$ for OER and $\boldsymbol{y}_{50 / 600}$ around $73 / 212 \mathrm{mV}$ for HER, small Tafel slopes of 46.1 and $41.1 \mathrm{mV} \mathrm{dec}^{-1}$, and prolonged catalytic durability in an alkaline medium because of the strong synergistic effects of $\mathrm{Zn}$ doping, multiple interface engineering, and integral threedimensional free-standing scaffold. As bifunctional catalysts, $\mathrm{NiFeZn-OH/NiZn-Ni/NF}$ required a low electrolytic voltage of $1.49 \mathrm{~V}$ at $20 \mathrm{~mA} \mathrm{~cm}^{-2}\left(1.61 \mathrm{~V}\right.$ at $\left.100 \mathrm{~mA} \mathrm{~cm}{ }^{-2}\right)$ with a sustained and stable output for $40 \mathrm{~h}$ during water splitting. This work might provide insights into the exploration of low-cost and highly efficient intermetallic/multimetallic hydroxide heterostructured electrocatalysts for practical overall water splitting.
\end{abstract}

Keywords: NiFeZn hydroxide, heterostructure, hydrogen evolution reaction, oxygen evolution reaction, overall splitting water

\section{INTRODUCTION}

Water electrolysis produces hydrogen and oxygen; it is a readily available mode, and water is an abundant resource, so this process has been widely explored [1]. Unfortunately, water splitting involves oxygen evolution reaction (OER) and hydrogen evolution reaction (HER), which are considered limiting factors because the multistep proton-coupled electron transfer in electrolysis commonly leads to a high energy barrier and sluggish reaction kinetics [2,3]. Noble metal-based electrocatalysts, such as $\mathrm{Ru} / \mathrm{Ir}$-based materials for OER and Pt-based materials for HER, possess excellent electrocatalytic performances. How- ever, high prices and rare reserves have seriously impeded their widespread practical applications in water electrolysis [4]. For this reason, various economic transition metal-based compounds, such as oxides [5], hydroxides [6], phosphides [7], sulfides [8], carbides [9], and selenides [10], have been developed for water splitting. Although OER and HER activities have been remarkably enhanced, forceful energy output cannot be easily obtained using different electrocatalysts in overall water splitting because the catalytic performance of most HER and OER electrocatalysts is commonly mismatched in the same media; consequently, the catalytic efficiency decreases. Therefore, highly active bifunctional electrocatalysts should be explored to achieve large-scale hydrogen production with costeffective and efficient processes.

Among various transition-metal compound electrocatalysts, $\mathrm{NiFe}$-based hydroxides have received great concerns because of their low overpotentials toward OER and abundant sources $[2,11]$. Introducing a third nonprecious metal (such as Mn [12], $\mathrm{Ce}$ [13], Zn [14], Zr [15], and Co [16]) into NiFe-based hydroxides can further decrease the overpotential and enhance the catalytic efficiency of OER because of the maximization of catalytic sites and modification of local coordination environment and electronic structures. Lim et al. [14] reported that the doping of $\mathrm{Zn}^{2+}$ into $\mathrm{NiFeO}_{x} \mathrm{H}_{y}$ dramatically enhances its OER activity and durability. They proposed that the type of strong Lewis acid species can modulate the electronic property of $\mathrm{NiFe}$ hydroxide to achieve a more appropriate intermediate binding during oxygen evolution. At present, $\mathrm{NiFe}$-based hydroxides have been regarded as a class of active nonprecious OER electrocatalysts in alkaline media because of their strong multimetallic synergistic effects [15]. However, their relatively inferior performance toward HER severely hampers their applications as bifunctional catalysts in water splitting. If the high HER performance can be achieved for NiFe-based hydroxides, such lowcost and widely available systems may open up broad opportunities for overall water splitting to hydrogen production. Few studies have found that incorporating extrinsic nonprecious metal NiFe-based hydroxides can yield acceptable bifunctional activities toward both OER and HER $[16,17]$. For example, Dinh et al. [17] reported that porous ultrathin ternary $\mathrm{NiFeV}$ layer double hydroxide nanosheets grown on nickel foam $(\mathrm{NiFeV}$ $\mathrm{LDH} / \mathrm{NF}$ ) deliver an enhanced bifunctional activity with over-

\footnotetext{
${ }^{1}$ Institute for Advanced Interdisciplinary Research (iAIR), Spintronics Institute, Collaborative Innovation Center of Technology and Equipment for Biological Diagnosis and Therapy in Universities of Shandong, University of Jinan, Jinan 250022, China

${ }^{2}$ State Key Laboratory of Crystal Materials, Shandong University, Jinan 250100, China

* Corresponding authors (emails: chm_xucx@ujn.edu.cn (Xu C); ifc_liuh@ujn.edu.cn (Liu H); shishenyan@sdu.edu.cn (Yan S))
} 
potentials of 231 and $125 \mathrm{mV}$ for OER and HER, respectively, at $10 \mathrm{~mA} \mathrm{~cm}^{-2}$ in $1.0 \mathrm{~mol} \mathrm{~L}^{-1} \mathrm{KOH}$ electrolyte compared with that of $\mathrm{NiFe}-\mathrm{LDH} / \mathrm{NF}$ and $\mathrm{NiV}-\mathrm{LDH} / \mathrm{NF}$. These findings suggest that novel bifunctional NiFe-based multimetallic hydroxides should be developed for overall water splitting with a stable operation and lower overpotentials in alkaline media.

Aside from incorporating a third nonprecious metal into $\mathrm{NiFe}$ hydroxide, well-defined microstructures can further improve the electrocatalytic activity and durability of water splitting [18]. Ternary metallic hydroxide nanomaterials are usually prepared through a wet chemical method using metallic salts as precursors with a common powder-type morphology [12,13]. Constructing self-supporting electrocatalysts on three-dimensional (3D) porous metal substrates is an effective and popular approach to avoid polymer binders from reducing electrocatalytic efficiency [19]. A 3D porous substrate is preferred to provide a highly conductive pathway and robust mechanical stability and increase the accessibility of catalytic sites $[13,20]$. Therefore, highly active bifunctional NiFe-based hydroxide electrocatalysts should be rationally designed for water splitting by incorporating a third metal and engineering nanostructure.

This study was performed to develop self-supported ternary $\mathrm{NiFeZn}$ hydroxide nanosheets using intermetallic NiZn and $\mathrm{Ni}$ heterojunction on a nickel foam surface (NiFeZn-OH/NiZn-Ni/ $\mathrm{NF})$ as a $3 \mathrm{D}$ substrate and precursor via a scalable electrodeposition-annealing-dealloying strategy. The bimodal intermetallic NiZn and Ni heterojunction on the NF surface were prepared through dealloying by electroplating $\mathrm{Zn}$ on NF, which functioned as a high-surface-area precursor to construct ternary $\mathrm{NiFeZn}$ hydroxide in situ through a one-step redox reaction with $\mathrm{FeCl}_{3}$ [21]. The bimodal NiZn/Ni heterojunction precursor could provide high-density reaction sites and participate in the multi-interface regulation of NiFeZn hydroxide to obtain a superior catalytic activity. Moreover, the self-supported architecture with abundant voids and channels was beneficial to the rapid mass transport and accelerated reaction kinetics during HER and OER electrocatalysis. With a robust 3D architecture, smooth mass transfer, and modulated electron structure between $\mathrm{NiZn/Ni}$ and NiFeZn hydroxide interface, the as-made NiFeZn$\mathrm{OH} / \mathrm{NiZn}-\mathrm{Ni} / \mathrm{NF}$ showed a high electrocatalytic performance with low overpotentials and small Tafel slopes in OER and HER. $\mathrm{NiFeZn-OH/NiZn-Ni/NF}$ as a highly active bifunctional catalyst required a low cell voltage to afford a high overall current density with a stable output. Thus, this work proposed a scalable and facile strategy to design highly active and stable intermetallic/multimetallic hydroxides for practical overall water splitting. This strategy presented the advantages of high reproducibility and cost-effective mass production.

\section{EXPERIMENTAL SECTION}

\section{Chemicals}

$\mathrm{RuO}_{2}$ nanoparticles and commercial Pt/C were purchased from Sigma Aldrich Chemical Reagent Co., Ltd. Other agents were bought from Shanghai Sinopharm Chemical Reagent Ltd., Co., China. All agents with analytical purity were used directly without further purification.

\section{Preparation of NiFeZn-OH/NiZn-Ni/NF}

$\mathrm{Zn}$ was electroplated for $1 \mathrm{~h}$, annealed, and etched to prepare $\mathrm{NiZn-Ni/NF}$ with the ratio of intermetallic NiZn and $\mathrm{Ni}$ of approximately 55.94:44.06 [21]. NiZn-Ni/NF was soaked in $20 \mathrm{~mL}$ of $25 \mathrm{mmol} \mathrm{L}^{-1} \mathrm{FeCl}_{3}$ solution at $25 \pm 1^{\circ} \mathrm{C}$ for $4 \mathrm{~h}$ to obtain NiFeZn-OH/NiZn-Ni/NF. For comparison, NiFe hydroxide nanosheets on $\mathrm{NF}(\mathrm{NiFe}-\mathrm{OH} / \mathrm{NF})$ were also made by immersing $\mathrm{NF}(1 \mathrm{~cm} \times 2 \mathrm{~cm})$ in $20 \mathrm{~mL}$ of $100 \mathrm{mmol} \mathrm{L}^{-1} \mathrm{FeCl}_{3}$ solution at $25 \pm 1{ }^{\circ} \mathrm{C}$ for $7 \mathrm{~h}$. The calculated loading mass of $\mathrm{NiFeZn-OH/NiZn-Ni/NF}$ was $\sim 2.2 \mathrm{mg} \mathrm{cm}^{-2}$.

\section{Characterization}

X-ray diffraction (XRD, Bruker D8 advanced) was conducted with $\mathrm{Cu} \mathrm{Ka}$ radiation $(\lambda=1.5418 \AA)$ at a step rate of $0.02^{\circ} \mathrm{s}^{-1}$. The microstructures and compositions of all samples were determined using a field-emission scanning electron microscope (SEM, Hitachi Regulus 8100) and an X-sight energy dispersive X-ray spectrometer (Oxford INCA). Electron backscatter diffraction (EBSD) was performed with an SEM (Quanta FEG 450) coupled with an EBSD acquisition system (Oxford Instruments). Transmission electron microscopy (TEM) was carried out on a JEOL JEM-ARF200F. X-ray photoelectron spectroscopy (XPS) was conducted using an ESCALAB MK II X-ray photoelectron spectrometer. The components were identified through inductively coupled plasma atomic emission spectrometry (ICP-AES, PerkinElmer Optima 8300).

\section{Electrochemical tests}

All electrochemical tests (Supplementary information, SI) were carried out on a CHI 760E electrochemical workstation (Shanghai Chenhua Co., China).

\section{RESULTS AND DISCUSSION}

\section{Preparation and characterization}

NF was chosen as the substrate because of its low cost, good electrical conductivity, and ample macropores. However, it has a micron-sized porous structure with a small specific surface area. As such, a dealloying strategy was first utilized to construct a new layer of a bimodal structure composed of intermetallic NiZn and $\mathrm{Ni}$ on the NF surface to further enlarge its specific surface area and synchronously introduce $\mathrm{Zn}$ by electrodepositing, annealing, and dissolving partial $\mathrm{Zn}$ atoms (Fig. 1). Then, NiZn$\mathrm{Ni} / \mathrm{NF}$ with $\mathrm{Zn}$ residues was immersed in the $\mathrm{FeCl}_{3}$ solution to grow ternary hydroxides in situ based on the redox reaction of $\mathrm{Ni}, \mathrm{Zn}$, and $\mathrm{Fe}^{3+}$.

Fig. S1 illustrates the structural evolution of the smooth-surface NF backbone to the rough NiZn alloy layer on NF with a $\mathrm{Zn}$ atomic content of 78.22 (Fig. S2). After NiZn/NF was etched, numerous uniform pores and channels $(1 \mu \mathrm{m})$ formed (Fig. $2 \mathrm{a}$ and inset). Many nanoscale ligaments/pores with a typical size of around $7 \mathrm{~nm}$ were newly formed (Fig. 2b), indicating the formation of a trimodal porous architecture consisting of an initial micron-scale 3D skeleton from $\mathrm{NF}$ and bimodal nanoscale ligaments/pores from the surface alloy layer of the NF skeleton. Fig. S3 shows the EBSD images, demonstrating that the intermetallic NiZn and Ni intercrossed through the porous surface with a molar ratio of $\sim 55.94: 44.06$. The element mapping images revealed that $\mathrm{Ni}$ and $\mathrm{Zn}$ were uniformly distributed with an atomic ratio of around 70.45:29.55 on the surface of NiZn-Ni/ NF (Fig. S4). Along with hydrolysis coprecipitation, the redox reaction of $\mathrm{Fe}^{3+}$ with the surface $\mathrm{Ni}$ and $\mathrm{Zn}$ subsequently produced NiFeZn hydroxide nanosheets. Furthermore, 2D curly nanosheet subunits with a thickness of dozens of nanometers 


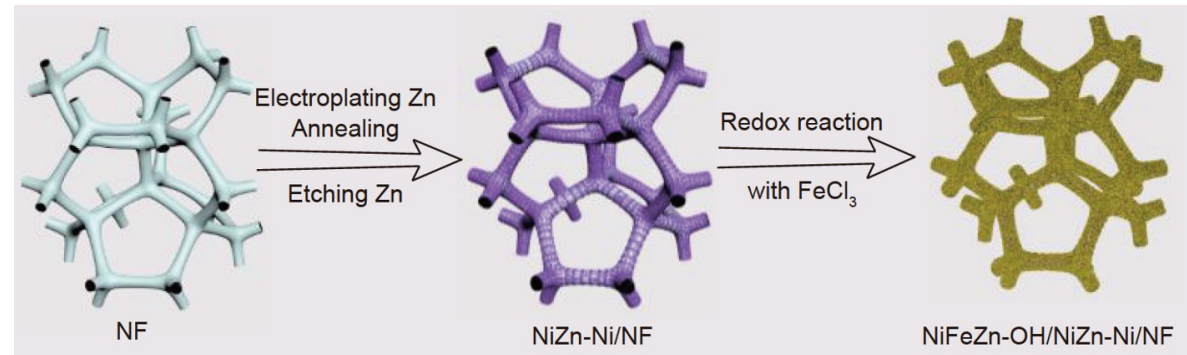

Figure 1 Schematic of the fabrication of a NiFeZn hydroxide nanosheet network grown on NiZn-Ni/NF.
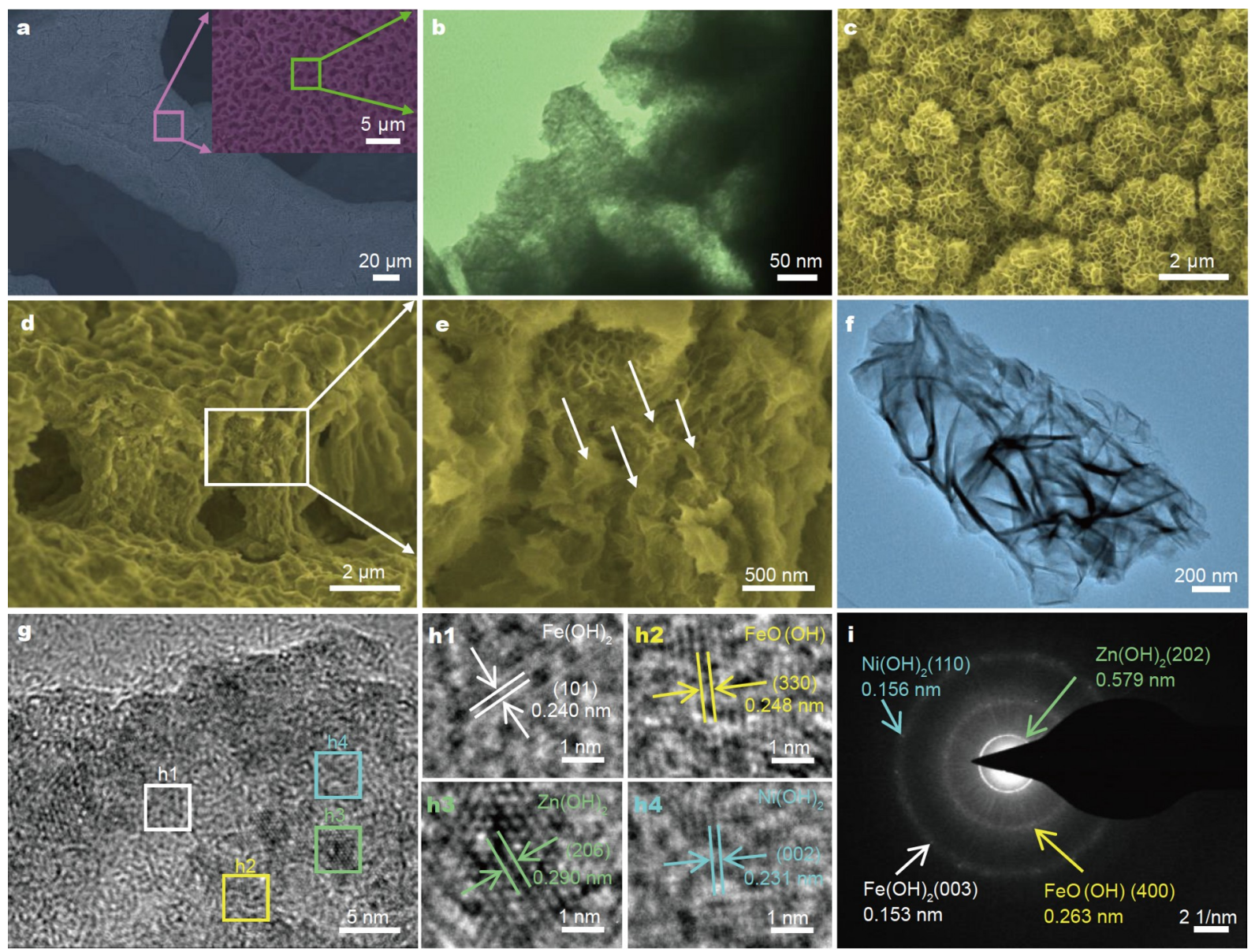

Figure 2 (a and inset) SEM and (b) TEM images of NiZn-Ni/NF. (c) SEM and (d, e) cross-section SEM images of NiFeZn-OH/NiZn-Ni/NF. (f) TEM and (g) HRTEM images of NiFeZn hydroxide nanosheets. (h1-h4) Corresponding enlarged parts of the square regions. (i) SAED pattern of NiFeZn hydroxide nanosheets.

interlaced to form one layer of a 3D multilevel nanosheet network array with embedded rich pores and channels (Fig. 2c). The thickness of the nanosheet network array was around $1 \mu \mathrm{m}$, and this array had a firm and integral anchor on the bimodal porous $\mathrm{NiZn}-\mathrm{Ni} / \mathrm{NF}$ to produce a high-surface-area interface (Fig. 2d, e). The TEM image in Fig. 2f further supported the structure of the hierarchical nanosheet network, where the bright region came from the pores, and the dark region could be ascribed to the interlaced nanosheets.

The high-resolution TEM (HRTEM) image in Fig. 2g presents the detailed texture of one nanosheet, where numerous ordered grains, whose main size was as small as $4 \mathrm{~nm}$, were randomly dispersed in the amorphous matrix, thereby forming a disordered/ordered crosslinking ensemble. Additionally, different kinds of lattice fringes could be identified, as marked by squares. The lattice fringes from different regions had a spacing of 0.240 , $0.248,0.290$, and $0.231 \mathrm{~nm}$ (Fig. $2 \mathrm{~h} 1-\mathrm{h} 4$ ), which could be ascribed to the (101), (330), (206), and (002) crystal planes of $\mathrm{Fe}(\mathrm{OH})_{2}, \mathrm{FeO}(\mathrm{OH}), \mathrm{Zn}(\mathrm{OH})_{2}$, and $\mathrm{Ni}(\mathrm{OH})_{2}$, respectively. In the corresponding selected area electron diffraction (SAED) pattern (Fig. 2i), where some of the characteristic diffraction points such as $\mathrm{Fe}(\mathrm{OH})_{2}(003), \mathrm{FeO}(\mathrm{OH})(400), \mathrm{Zn}(\mathrm{OH})_{2}(202)$, and $\mathrm{Ni}(\mathrm{OH})_{2}$ (110) can be clearly seen as denoted. Moreover, the diffuse rings with circular diffraction spots further verified the amorphous 
nature with numerous dispersed nanocrystals. This finding was also consistent with the XRD result shown below. The amorphous body is preferred to the crystalized state because of its superior activity [22]. Elemental mapping (Fig. S5) revealed the homogeneous distribution of $\mathrm{Ni}, \mathrm{Fe}, \mathrm{Zn}$, and $\mathrm{O}$ in the nanosheet network array peeled off by ultrasonic treatment. ICP analysis indicated that the atomic ratio of $\mathrm{Ni}, \mathrm{Fe}$, and $\mathrm{Zn}$ was 29.98:53.12:16.90 in the hydroxide nanosheets. NiFe-OH/NF also had a well-distributed nanosheet network structure anchored on NF via a one-step redox reaction between NF and $\mathrm{FeCl}_{3}$ solution (Fig. S6). The whole reaction was expressed as follows: $\mathrm{Zn}+2 \mathrm{Fe}^{3+} \rightarrow \mathrm{Zn}^{2+}+2 \mathrm{Fe}^{2+}(1), \mathrm{Ni}+2 \mathrm{Fe}^{3+} \rightarrow \mathrm{Ni}^{2+}+$ $2 \mathrm{Fe}^{2+}(2), 4 \mathrm{Fe}^{2+}+2 \mathrm{H}_{2} \mathrm{O}+\mathrm{O}_{2} \rightarrow 4 \mathrm{Fe}^{3+}+4 \mathrm{OH}^{-}(3), \mathrm{Fe}^{2+}+\mathrm{Fe}^{3+}+$ $\mathrm{Ni}^{2+}+\mathrm{Zn}^{2+}+\mathrm{OH}^{-} \rightarrow \mathrm{NiFeZn-OH}$ (4). During the reaction, $\mathrm{Ni}$ and $\mathrm{Zn}$ uniformly distributed on NF were oxidized by $\mathrm{Fe}^{3+}$. The generated metallic ions underwent hydrolysis and grew together to form a uniform nanosheet network. The whole preparation was simple and highly reproducible. Furthermore, it had a high yield, could be used for mass production, and did not require any extra agents at ambient temperature. The effects of the $\mathrm{FeCl}_{3}$ solution concentration and reaction time on the resulting structure were explored (Fig. S7). A detailed description is provided in the SI.

$\mathrm{XRD}$ was applied to investigate the evolution of phase structures and components during the formation of the NiFeZn-OH/ $\mathrm{NiZn-Ni/NF}$ sample. After $\mathrm{Zn}$ was electroplated on NF, the diffraction peaks of $\mathrm{Zn}$ appeared (Fig. S8a), and many diffraction peaks of intermetallic $\beta_{1}-\mathrm{NiZn}$ and $\gamma-\mathrm{NiZn}_{3}$ newly emerged on $\mathrm{NF}$ after annealing (Fig. 3a) [23]. $\beta_{1}-\mathrm{NiZn}$ intermetallic residues formed as the diffraction peaks of metallic $\mathrm{Ni}$ emerged upon dealloying (Fig. 3b). No evident diffraction peaks related to $\mathrm{NiFeZn}$ hydroxide occurred upon redox reaction because of its amorphous matrix despite the existence of many structurally ordered nanoscale domains, as observed in the HRTEM image [24]. NiFe hydroxide in NiFe-OH/NF also had low crystallinity (Fig. S8b) [11].

XPS was conducted to further investigate the surface chemical states of NiZn-Ni/NF, NiFe-OH/NF, and NiFeZn-OH/NiZn-Ni/ $\mathrm{NF}$. From the Ni $2 \mathrm{p}_{3 / 2}$ region in $\mathrm{NiZn}-\mathrm{Ni} / \mathrm{NF}$, the peaks can be assigned to metallic $\mathrm{Ni}$ and $\mathrm{Ni}^{2+}$ species (Fig. 3c) [25]. The bond energy of $\mathrm{Ni}^{0}$ in NiZn-Ni/NF negatively shifted by $0.36 \mathrm{eV}$ compared with that of pure Ni. For Zn $2 \mathrm{p}$ (Fig. $3 \mathrm{~d}$ ), the $2 \mathrm{p}_{3 / 2}$ peak at $1021.60 \mathrm{eV}$ could be assigned to metallic $\mathrm{Zn}$ with a positive shift of $0.43 \mathrm{eV}$ compared with that of pure $\mathrm{Zn}$ [26]. The bond energy shifts of $\mathrm{Ni}$ and $\mathrm{Zn}$ stemmed from the formation of intermetallic NiZn. After the redox reaction with $\mathrm{FeCl}_{3}$, the $2 \mathrm{p}_{3 / 2}$ and $2 \mathrm{p}_{1 / 2}$ of the $\mathrm{Ni}^{2+}$ peak suffered from slight negative shifts of about 0.16 and $0.09 \mathrm{eV}$ (Fig. 3e). This result indicated a change in the electronic structure of $\mathrm{Ni}$ after $\mathrm{Zn}$ incorporation. For the Fe 2p in Fig. 3e, the peaks at 710.44 and $723.80 \mathrm{eV}$ could be ascribed to $\mathrm{Fe}(\mathrm{OH})_{2}$ [27], and the peaks at 713.04 and $726.99 \mathrm{eV}$ could be attributed to $\mathrm{FeOOH}$ [28]. The binding energies of $\mathrm{Fe}^{2+} 2 \mathrm{p}_{3 / 2}$ and $2 \mathrm{p}_{1 / 2}$ negatively shifted by 0.13 and $0.12 \mathrm{eV}$ after $\mathrm{Zn}$ introduction. These negative shifts confirmed the influence of $\mathrm{Zn}$ doping and intense electronic interactions between the interfaces of NiZn-Ni/NF and NiFeZn$\mathrm{OH}$. From the $\mathrm{Zn} 2 \mathrm{p}$ core level of NiFeZn-OH/NiZn-Ni/NF in Fig. 3d, two peaks at 1021.57 and $1044.62 \mathrm{eV}$ could be assigned to $\mathrm{Zn}^{2+}$ from $\mathrm{Zn}(\mathrm{OH})_{2}$ [29]. From the O 1s in Fig. 3f, the peaks centered at 529.16 and $530.84 \mathrm{eV}$ came from the metal-oxygen bonds $(\mathrm{M}-\mathrm{O})$ and the bound hydroxide groups $(\mathrm{M}-\mathrm{OH})$ [30], and the peak at $532.46 \mathrm{eV}$ is possibly related to water adsorbed on the sample surface [27]. By comparison, the bond energy of $\mathrm{O}$ shifted to a lower direction than those of NiZn-Ni/NF and
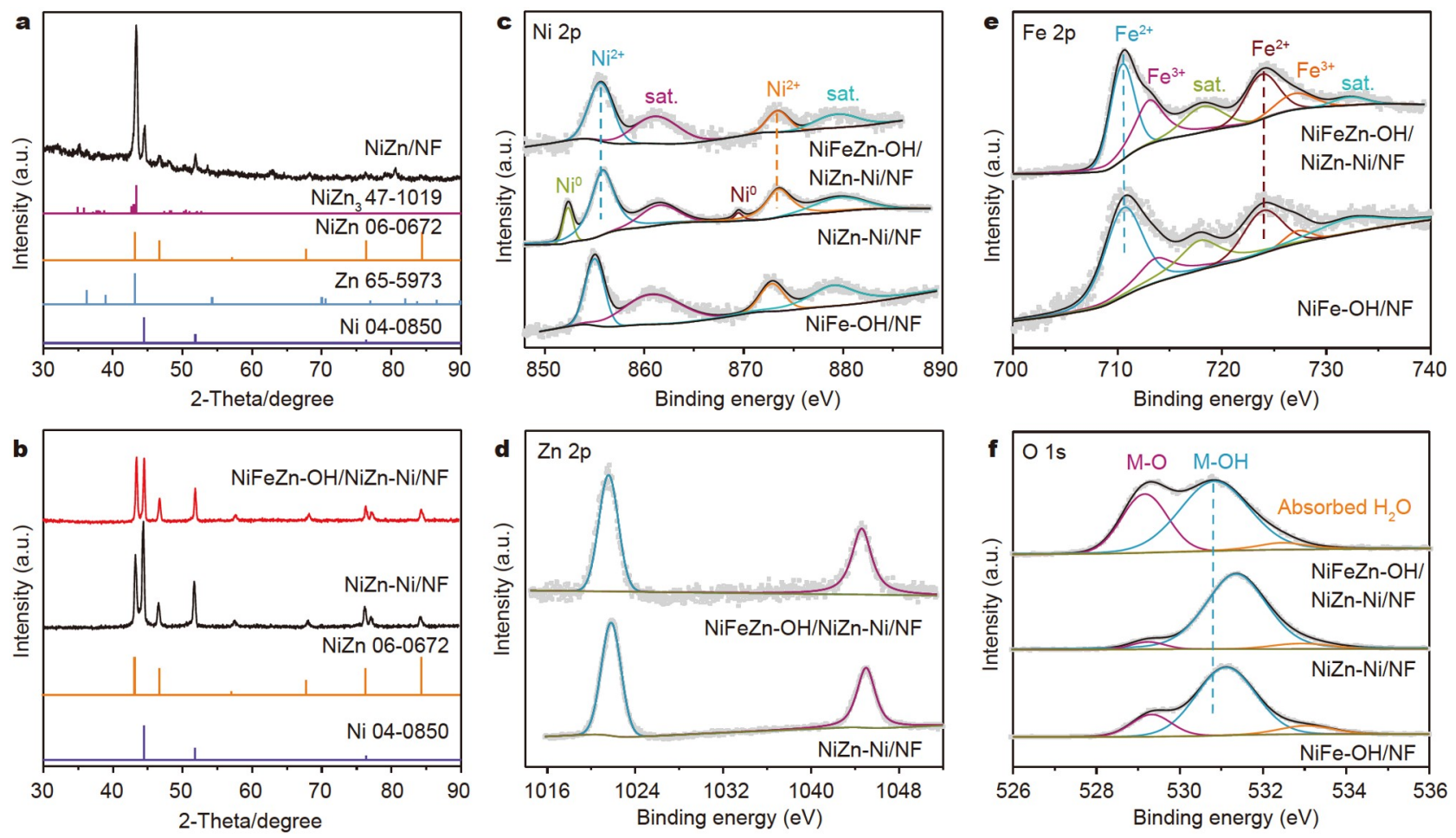

Figure 3 XRD patterns of (a) NiZn/NF, (b) NiZn-Ni/NF, and NiFeZn-OH/NiZn-Ni/NF samples. XPS data of (c) Ni 2p, (d) Zn 2p, (e) Fe 2p, and (f) O 1s for $\mathrm{NiFeZn-OH/NiZn-Ni/NF,} \mathrm{NiFe-OH/NF,} \mathrm{and} \mathrm{NiZn-Ni/NF.}$ 
$\mathrm{NiFe}-\mathrm{OH} / \mathrm{NF}$. The negative shifts for $\mathrm{Ni}, \mathrm{Fe}$, and $\mathrm{O}$ indicated the strong interfacial electronic interactions between $\mathrm{NiZn-Ni}$ and $\mathrm{NiFeZn}$ hydroxide, and such interactions are necessary to accelerate the charge transfer in water splitting. Based on these observations, XPS data further confirmed the successful formation of ternary hydroxide and modulated electronic structures compared with the $\mathrm{NiFe}-\mathrm{OH} / \mathrm{NF}$ sample, which is more favorable for the fast reaction kinetics.

\section{Electrocatalytic activity tests}

Fig. 4a shows the linear sweep voltammetry (LSV) curves of OER with $i R$ correction for all comparative samples. NiFeZn$\mathrm{OH} / \mathrm{NiZn}-\mathrm{Ni} / \mathrm{NF}$ displays an optimal electrocatalytic activity with a lower onset potential and a larger current density at the same overpotential. Notably, it can deliver a current density as high as $600 \mathrm{~mA} \mathrm{~cm}^{-2}$ with the required overpotential of only $284 \mathrm{mV}$, which is valuable regarding the industrial need for the large current density output. In addition, it has output current densities of 50 and $100 \mathrm{~mA} \mathrm{~cm}{ }^{-2}$ under the overpotentials of 235 and $254 \mathrm{mV}$, which are obviously lower than those of other samples (Fig. 4b). By comparison, ternary NiFeZn hydroxide constructed on the NiZn-Ni/NF surface serves as active sites for an excellent OER performance, which is also superior to the performance of many representative analogs (Table S1) $[2,11,12,15,20,29,31-39]$. These results indicated that the asdesigned materials with an integrated $3 \mathrm{D}$ nanosheet network could achieve a high electrocatalytic performance toward oxygen evolution.

Among the samples, NiFeZn-OH/NiZn-Ni/NF had the smallest Tafel slope of $46.1 \mathrm{mV} \mathrm{dec}^{-1}$ (Fig. 4c), further suggesting its high intrinsic activity for OER [22]. It also had the smallest charge transfer resistance $\left(R_{\mathrm{ct}} ;\right.$ Fig. $\left.4 \mathrm{~d}, \mathrm{e}\right)$, implying a much faster charge transfer during the electrocatalytic process, possibly because of the rapid mass and electron transport along the integrated interface between the well-conductive $\mathrm{NiZn-Ni/NF}$ substrate and NiFeZn-OH nanosheet network. The catalytic behavior of one electrocatalyst is considered to be closely related to its electrochemical active surface area (ECSA). Therefore,
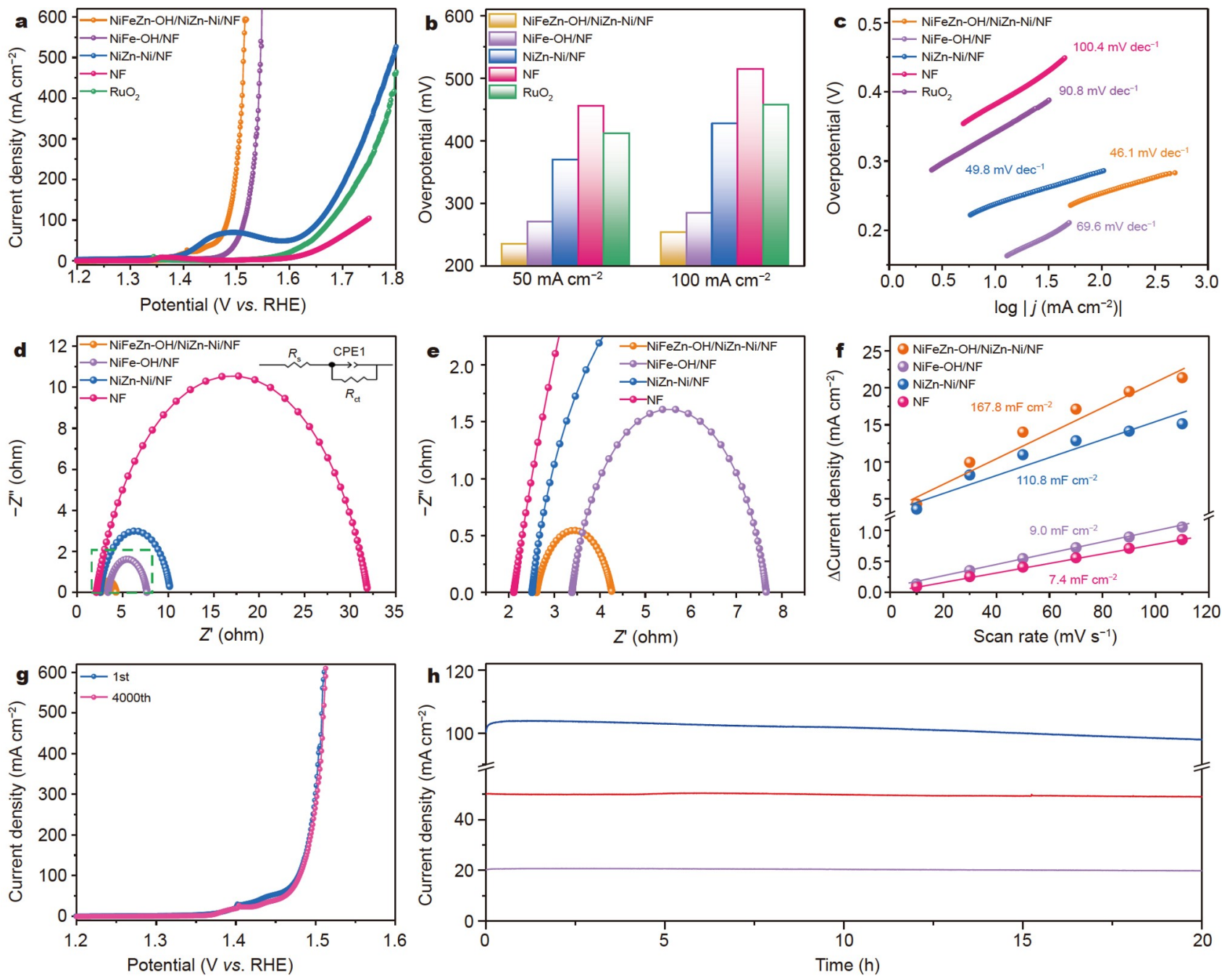

Figure 4 (a) LSV curves, (b) overpotentials at 50 and $100 \mathrm{~mA} \mathrm{~cm}{ }^{-2}$, and (c) Tafel plots of NiFeZn-OH/NiZn-Ni/NF, NiZn-Ni/NF, NiFe-OH/NF, RuO , and $\mathrm{NF}$ toward OER in $1.0 \mathrm{~mol} \mathrm{~L}^{-1} \mathrm{KOH}$ solution with $i R$ compensation at a scan rate of $5 \mathrm{mV} \mathrm{s}^{-1}$. (d) Electrochemical impedance spectroscopy (EIS) data at the overpotential of $300 \mathrm{mV}$ for the as-made samples and (e) an enlarged image of the dashed frame. (f) Capacitive current at $1.174 \mathrm{~V} v$. reversible hydrogen electrode (RHE) at different scan rates for NiFeZn-OH/NiZn-Ni/NF, NiFe-OH/NF, NiZn-Ni/NF, and NF. (g) LSV curves of NiFeZn-OH/NiZn-Ni/NF at a scan rate of $5 \mathrm{mV} \mathrm{s}^{-1}$ before and after the test for $4000 \mathrm{CV}$ cycles. (h) Current-time curves of NiFeZn-OH/NiZn-Ni/NF under the potentials of $1.498,1.556$, and $1.658 \mathrm{~V}$ for $20 \mathrm{~h}$, respectively. 
cyclic voltammetry $(\mathrm{CV})$ tests were conducted at different scanning rates to obtain double-layer capacitance $\left(C_{\mathrm{dl}}\right)$ (Fig. S9), which is directly proportional to the ECSA [2]. Among all samples, NiFeZn-OH/NiZn-Ni/NF had the largest $C_{\mathrm{dl}}$ of $167.8 \mathrm{mF} \mathrm{cm}^{-2}$, which was $18.6,1.5$, and 22.7 times those of $\mathrm{NiFe}-\mathrm{OH} / \mathrm{NF}, \mathrm{NiZn}-\mathrm{Ni} / \mathrm{NF}$, and NF, respectively (Fig. 4f). This result confirmed that the in situ construction of ternary NiFeZn hydroxide on bimodal porous $\mathrm{NiZn/Ni}$ could generate many exposed active sites and greatly enhance the OER performance.

Apart from excellent catalytic activities, long-term durability is an important criterion for electrocatalysts in practical water splitting. In this study, the polarization curves of NiFeZn-OH/ $\mathrm{NiZn-Ni/NF}$ nearly overlapped with each other before and after $4000 \mathrm{CV}$ cycles (Fig. 4g). After constant oxygen evolution for $20 \mathrm{~h}$ under different fixed potentials, the current densities remained at $99.3 \%, 98.0 \%$, and $97.2 \%$ compared with the initial density, respectively, further indicating the high catalytic durability of NiFeZn-OH/NiZn-Ni/NF (Fig. 4h).

In alkaline media, OER is a surface process involving a fourstep proton-coupled electron transfer [39]: $\mathrm{M}+\mathrm{OH}^{-} \rightarrow \mathrm{MOH}+$ $\mathrm{e}^{-}(1), \mathrm{MOH}+\mathrm{OH}^{-} \rightarrow \mathrm{MO}+\mathrm{H}_{2} \mathrm{O}+\mathrm{e}^{-}(2), \mathrm{MO}+\mathrm{OH}^{-} \rightarrow$ $\mathrm{MOOH}+\mathrm{e}^{-}(3)$, and $\mathrm{MOOH}+\mathrm{OH}^{-} \rightarrow \mathrm{M}+\mathrm{O}_{2}+\mathrm{H}_{2} \mathrm{O}+\mathrm{e}^{-}$(4). Bonding interactions ( $\mathrm{M}-\mathrm{O})$ are vital for the catalytic behavior of these intermediates during an OER process, so the surface structure of one catalyst can strongly affect the electrocatalytic performance [35]. Our results showed that NiFeZn-OH/NiZn$\mathrm{Ni} / \mathrm{NF}$ possessed ideal catalytic kinetics and dramatically enhanced the OER activity. Besides the highly efficient mass transfer from structural superiorities, the accelerated oxygenevolving kinetics and distinct OER performance of NiFeZn-OH/ $\mathrm{NiZn-Ni/NF}$ were successfully obtained through electron structure modulation through interface engineering and $\mathrm{Zn}$ doping.

The electrocatalytic performance of all catalysts toward HER was further assessed in the same media. As indicated by the LSV curves in Fig. 5a, the current density of NiFeZn-OH/NiZn-Ni/ $\mathrm{NF}$ at the same overpotential was higher than that of the other samples, and the onset overpotential of the former was lower than that of the latter, as observed in the OER. It only required an overpotential of only $212 \mathrm{mV}$ at $600 \mathrm{~mA} \mathrm{~cm}^{-2}$. Besides, it achieved the current densities of 50 and $100 \mathrm{~mA} \mathrm{~cm}^{-2}$ at lower overpotentials of 73 and $99 \mathrm{mV}$ (Fig. 5b), respectively. However, in the same case, larger overpotentials of $260 / 301,121 / 144$, and 288/344 mV were needed for NiFe-OH/NF, NiZn-Ni/NF, and $\mathrm{NF}$, respectively. In our previous study, NiZn-Ni/NF has a high HER activity [21]. Herein, the enhanced HER activity of $\mathrm{NiFeZn-OH/NiZn-Ni/NF}$ verified that the introduction of NiFeZn hydroxide improved the HER activity. Therefore, NiZn$\mathrm{Ni}$ heterojunction and NiFeZn-OH act together as active sites toward hydrogen evolution. The HER activity of NiFeZn-OH/ $\mathrm{NiZn}-\mathrm{Ni} / \mathrm{NF}$ is not as good as that of $\mathrm{Pt} / \mathrm{C}$ in the region of current densities lower than $170 \mathrm{~mA} \mathrm{~cm}^{-2}$; however, it outperforms $\mathrm{Pt} / \mathrm{C}$ when a much higher current density is required because $\mathrm{Pt} / \mathrm{C}$ commonly peels off from the NF as a result of the generation of massive bubbles at high current densities. This phenomenon also demonstrates that a self-supporting structure is preferable for high-output hydrogen production at an industrial scale. The HER activity of NiFeZn-OH/NiZn-Ni/NF is comparable to that of a $\mathrm{Pt} / \mathrm{C}$ catalyst, even superior to numerous nonprecious metal compound electrocatalysts, as shown in Table S2 [20,29,36,39-49].

The HER process in an alkaline solution can be expressed in the following reaction mechanism [50]: $\mathrm{H}_{2} \mathrm{O}+\mathrm{e}^{-}+\mathrm{M} \rightarrow \mathrm{H}-\mathrm{M}+$ $\mathrm{OH}^{-}$(Volmer step, $\left.120 \mathrm{mV} \mathrm{dec}{ }^{-1}\right), \mathrm{H}-\mathrm{M}+\mathrm{H}_{2} \mathrm{O}+\mathrm{e}^{-} \rightarrow \mathrm{H}_{2}+$
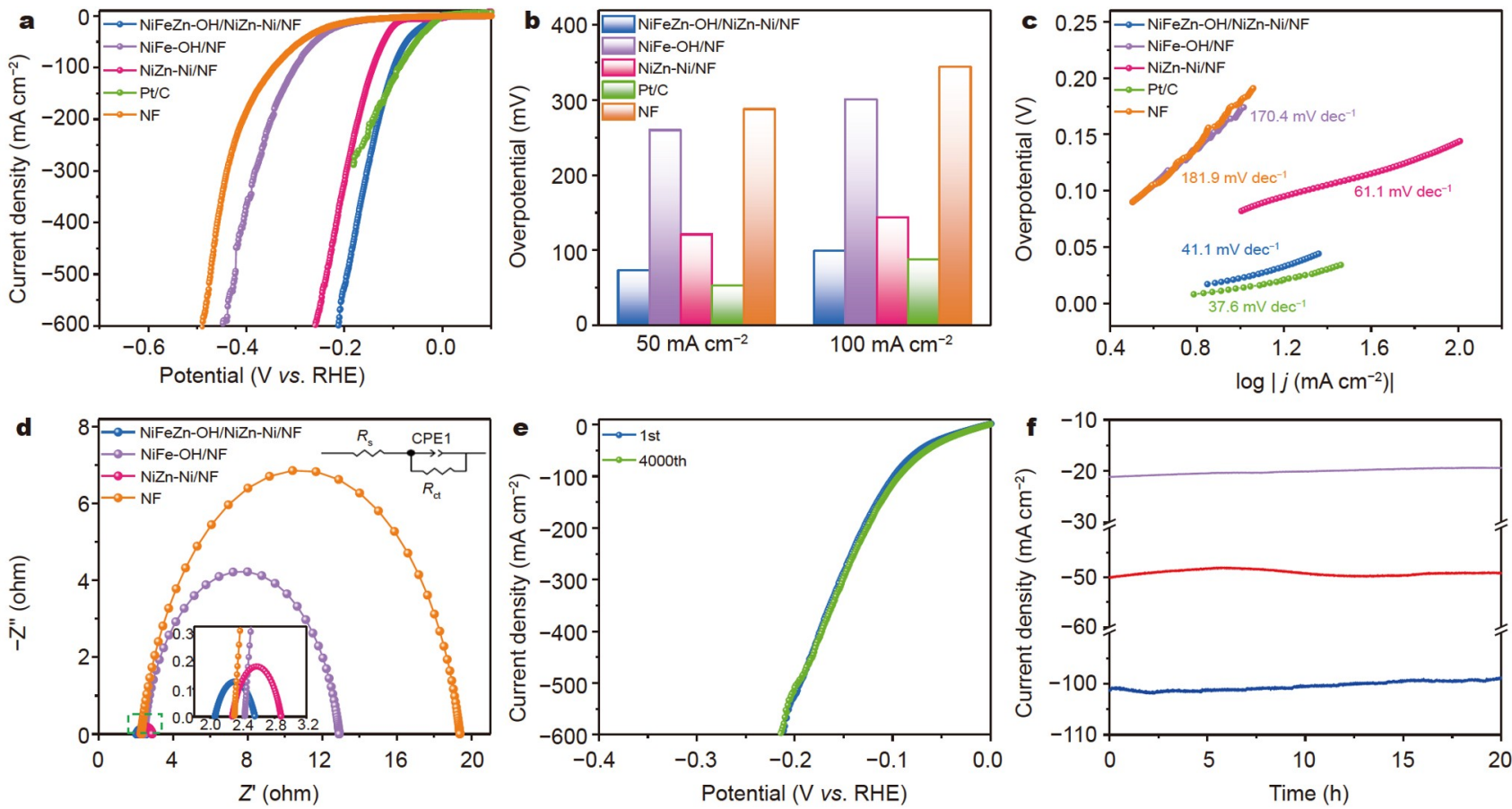

Figure 5 (a) LSV curves, (b) overpotentials at 50 and $100 \mathrm{~mA} \mathrm{~cm}{ }^{-2}$, and (c) Tafel plots of NiFeZn-OH/NiZn-Ni/NF, NiFe-OH/NF, NiZn-Ni/NF, Pt/C, and $\mathrm{NF}$ toward HER in $1.0 \mathrm{~mol} \mathrm{~L}^{-1} \mathrm{KOH}$ solution with $i R$ compensation at a scan rate $5 \mathrm{mV} \mathrm{s}^{-1}$. (d) EIS data at the overpotential of $250 \mathrm{mV}$ for the as-made samples. (e) LSV curves of NiFeZn-OH/NiZn-Ni/NF at a scan rate of $5 \mathrm{mV} \mathrm{s} \mathrm{s}^{-1}$ before and after the test for $4000 \mathrm{CV}$ cycles. (f) Current-time curves of NiFeZn$\mathrm{OH} / \mathrm{NiZn}-\mathrm{Ni} / \mathrm{NF}$ under the potentials of $-0.087,-0.176$, and $-0.255 \mathrm{~V}$ for $20 \mathrm{~h}$, respectively. 
$\mathrm{OH}^{-}+\mathrm{M}$ (Heyrovsky step, $40 \mathrm{mV} \mathrm{dec}{ }^{-1}$ ), and $\mathrm{H}-\mathrm{M}+\mathrm{H}-\mathrm{M} \rightarrow$

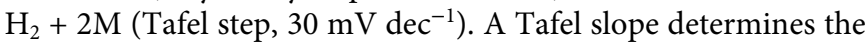
rate-limiting step of the HER pathway as an inherent property of electrocatalysts. Therefore, when the Volmer reaction is the ratelimiting step of HER, the Tafel slope should be $120 \mathrm{mV} \mathrm{dec}^{-1}$. Conversely, when the Heyrovsky or Tafel reaction is the ratelimiting step, the Tafel slope should be 40 or $30 \mathrm{mV} \mathrm{dec}^{-1}$. In Fig. $5 c$, the Tafel slope of NiFeZn-OH/NiZn-Ni/NF for HER was $41.1 \mathrm{mV} \mathrm{dec}^{-1}$, which was close to $37.6 \mathrm{mV} \mathrm{dec}{ }^{-1}$ of $\mathrm{Pt} / \mathrm{C}$. This result indicated that the Heyrovsky reaction was the ratedetermining step, which was the advantageous kinetics of HER.

The $R_{\text {ct }}$ of NiFeZn-OH/NiZn-Ni/NF was smaller $(0.5 \Omega)$ than those of $\mathrm{NiFe}-\mathrm{OH} / \mathrm{NF}(10.5 \Omega)$, NiZn-Ni/NF $(0.6 \Omega)$, and $\mathrm{NF}$ $(17.1 \Omega)$. This finding revealed its faster charge transfer during HER (Fig. 5d). Its electrocatalytic activity had almost no evident decline after $4000 \mathrm{CV}$ cycles (Fig. 5e). Moreover, current-time curves at different fixed potentials further showed its prolonged catalytic durability with almost no current loss upon a continuous reaction for $20 \mathrm{~h}$ (Fig. 5f).

With the outstanding OER and HER performance of NiFeZn$\mathrm{OH} / \mathrm{NiZn}-\mathrm{Ni} / \mathrm{NF}$, the electrolyzer of the overall water splitting was developed and used as the cathode and anode in a twoelectrode system. As shown in Fig. 6a, only a voltage of $1.49 \mathrm{~V}$ was required to achieve a current density of $20 \mathrm{~mA} \mathrm{~cm}^{-2}$, which was lower than those of NiFeZn-OH/NiZn-Ni/NF (+)\|NiZn-Ni/ $\mathrm{NF}(-)(1.53 \mathrm{~V})$ and commercially available $\mathrm{RuO}_{2}(+) \| \mathrm{Pt} / \mathrm{C}(-)$
$(1.64 \mathrm{~V})$. Besides, it can deliver the current density of $100 \mathrm{~mA} \mathrm{~cm}^{-2}$ under the potential of $1.61 \mathrm{~V}$ for this electrode, which was much lower than those of the two other electrolyzers. In addition, the as-constructed target device showed negligible decay after $40 \mathrm{~h}$ of long-term continuous testing at $1.52 \mathrm{~V}$ (Fig. 6b). It also had the most optimal output stability among the three electrolyzers. The electrocatalytic performance of NiFeZn$\mathrm{OH} / \mathrm{NiZn-Ni/NF}$ was better than most similar electrocatalysts for overall water splitting (Fig. 6c and Table S3), indicating its remarkable superiority as a bifunctional catalyst $[5,20,27,36,39,41,42,44-48,51]$.

The cause of the exceptional catalytic durability of NiFeZn$\mathrm{OH} / \mathrm{NiZn}-\mathrm{Ni} / \mathrm{NF}$ in water electrolysis was explored using the OER anode as a representative. The SEM image after the stability test (Fig. S10a) indicated that the structure of the nanosheet network was mostly retained. Our comparison revealed that the nanosheet network is slightly dissolved and aggregated, which usually occurs in NiFe-based hydroxides [1,2]. In alkaline solutions, $\mathrm{OH}^{-}$can diffuse into hydroxide nanosheet interlayers and stimulate the local acidic surroundings; consequently, $\mathrm{OH}^{-}$ dissolves [1]. ICP analysis confirmed that the atomic ratio of $\mathrm{Ni}$, $\mathrm{Fe}$, and $\mathrm{Zn}$ in the post-test hydroxide nanosheets was approximately 34.02:47.95:18.03. Compared with that of the fresh sample, the Fe content slightly decreased, whereas the $\mathrm{Ni}$ and $\mathrm{Zn}$ contents increased. This result might be attributed to the relatively severe dissolution of $\mathrm{Fe}$ from NiFeZn hydroxides in the
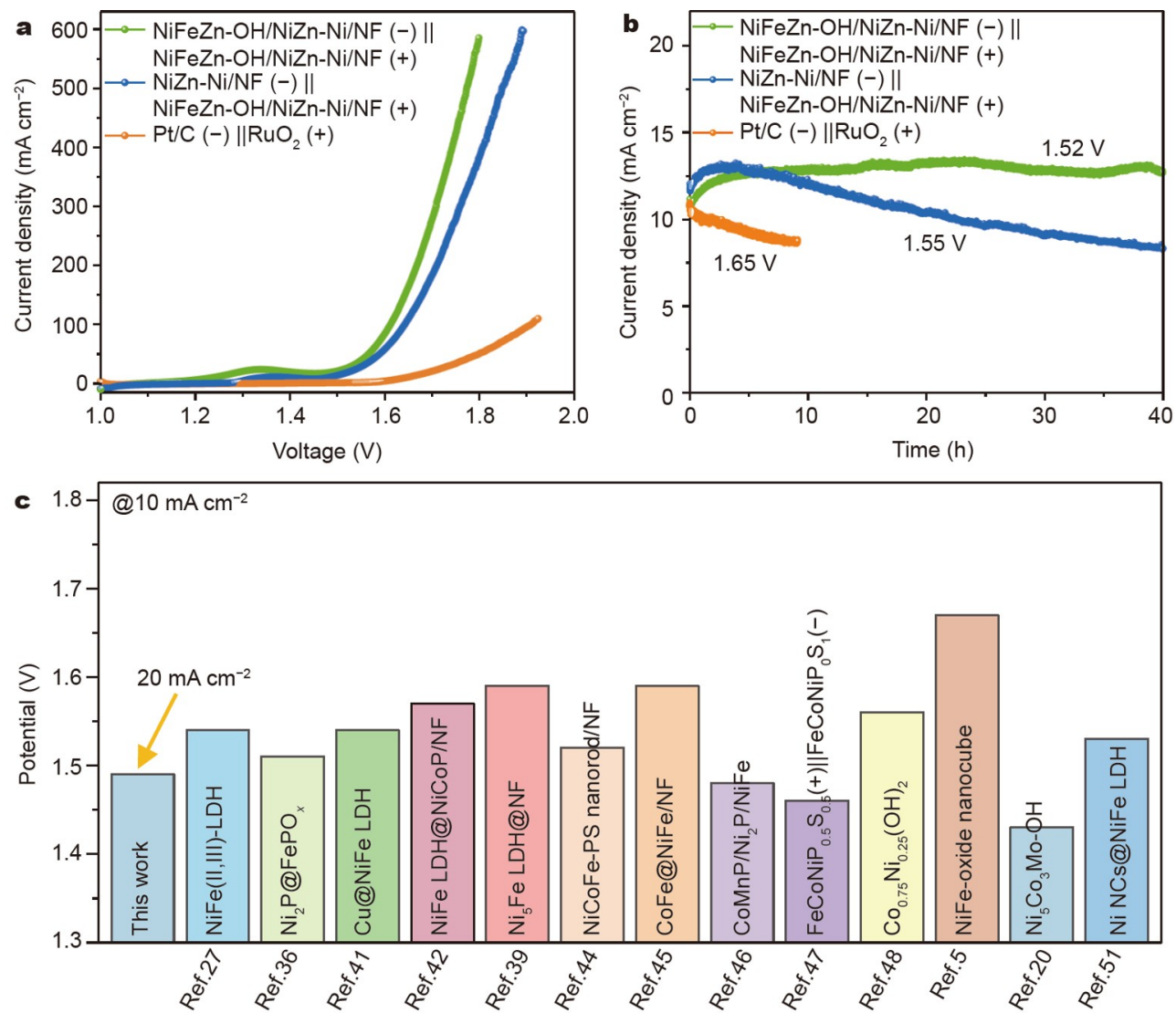

Figure 6 (a) LSV curves of the overall water splitting of NiFeZn-OH/NiZn-Ni/NF, NiFeZn-OH/NiZn-Ni/NF $(+) \| \mathrm{NiZn}-\mathrm{Ni} / \mathrm{NF}(-)$, and RuO $2(+)|| \mathrm{Pt} / \mathrm{C}(-)$ in a two-electrode device. (b) Current-time curves of NiFeZn-OH/NiZn-Ni/NF, NiFeZn-OH/NiZn-Ni/NF (+)\|NiZn-Ni/NF $(-)$, and RuO $(+) \| \mathrm{Pt} / \mathrm{C}(-)$ at constant potentials of 1.52, 155, and $1.65 \mathrm{~V}$ in a two-electrode configuration, respectively. (c) Cell voltage (@10 mA cm ${ }^{-2}$ ) comparison of recently reported bifunctional electrocatalysts in Table S3. 
electrolyte. In addition, the residual elements in the electrolyte were measured after the stability test. $\mathrm{Ni}, \mathrm{Fe}$, and $\mathrm{Zn}$ were almost undetected in the resulting electrolyte, possibly because the relatively large amounts of electrolytes were used during long periods of the stability test. During the test, the slight dissolution of the catalyst yielded a low concentration in the electrolyte, so the dissolved ions could not be detected. The XRD pattern obtained after the stability test showed that the amorphous nature of NiFeZn-OH/NiZn-Ni/NF was still preserved upon the continuous electrocatalytic reaction (Fig. S10b). The XPS in Fig. S1la indicated that the $\mathrm{Ni}^{2+}$ content in the $\mathrm{Ni} 2 \mathrm{p}$ region slightly reduced as the $\mathrm{Ni}^{3+}$ species emerged; as such, $\mathrm{Ni}(\mathrm{OH})_{2}$ was slightly oxidized during oxygen evolution. The change in $\mathrm{Zn} 2 \mathrm{p}$ and Fe $2 \mathrm{p}$ could be disregarded compared with the fresh sample (Fig. S11b, c). For O 1s in Fig. S11d, the M-O bond obviously increased after the stability test, implying that hydroxide was partially oxidized to $\mathrm{M}-\mathrm{O}-\mathrm{OH}$ under oxidative conditions, which is usually thought to be the real catalytically active sites for water splitting [22]. These results suggested that $\mathrm{NiZn-Ni/NF}$ could robustly adhere to the NiFeZn-OH nanosheet network. The bulky integral 3D architecture possessed high corrosion resistance and mechanical stability under strong oxidizing environments.

Our study demonstrated that NiFeZn-OH/NiZn-Ni/NF as a bifunctional electrocatalyst exhibited an outstanding catalytic activity, high structural stability, and exceptional device performance in alkaline electrolytes. Its outstanding OER and HER performances were likely attributed to its structural and compositional originalities. A highly conducive $3 \mathrm{D}$ scaffold with microscale hollow channels and rich voids embedded in the nanosheet network could accelerate the evolution/release of gas molecules during HER and OER, thus promoting the reaction kinetics. The 2D thin nanosheet subunits and rich voids as reservoirs could provide high-density active sites and enough contact with electrolytes. The assembly between the bulky multilevel 3D scaffold and nanosheet network had high corrosion resistance and robust structural stability, resulting in high structural stability and device performance. In addition, the synergistic effects of $\mathrm{Ni}, \mathrm{Fe}$, and $\mathrm{Zn}$ hydroxides and modulation of electron structures through interface engineering and $\mathrm{Zn}$ doping could create multiple active sites with high activity; thus, the electrocatalytic kinetics of NiFeZn-OH/NiZn-Ni/NF could be modified for OER and HER. Lastly, an amorphous texture with numerous ordered nanoscale grains of NiFeZn hydroxide possibly contributed to the adsorption/desorption of reactants and superior bifunctional activity.

\section{CONCLUSIONS}

In summary, a ternary $\mathrm{NiFeZn}$ hydroxide nanosheet network anchored on the hierarchical porous $\mathrm{NiZn} / \mathrm{Ni}$ and having remarkable electrocatalytic activities toward water splitting was successfully prepared by dealloying and a redox reaction. With a crosslinking hydroxide nanosheet array, a hierarchical porous substrate, interface engineering, and synergistic effects of $\mathrm{Ni}, \mathrm{Fe}$, and $\mathrm{Zn}$ species, NiFeZn-OH/NiZn-Ni/NF exhibited lower overpotentials at high current densities, smaller Tafel slopes, and stable catalytic durability toward OER and HER. In particular, its constructed electrolyzer possessed an outstanding performance toward the overall water splitting with a smaller required cell voltage and prolonged output. Our work provided insights into the development of novel and highly active bifunctional electrocatalysts for practical and economic hydrogen production via water splitting.

Received 12 October 2021; accepted 7 December 2021; published online 29 December 2021

1 Chen R, Hung S, Zhou D, et al. Layered structure causes bulk NiFe layered double hydroxide unstable in alkaline oxygen evolution reaction. Adv Mater, 2019, 31: 1903909

2 Niu S, Jiang W, Tang T, et al. Autogenous growth of hierarchical $\mathrm{NiFe}(\mathrm{OH})_{x} / \mathrm{FeS}$ nanosheet-on-microsheet arrays for synergistically enhanced high-output water oxidation. Adv Funct Mater, 2019, 29: 1902180

3 Gao W, Yang M, Chi J, et al. In situ construction of surface defects of carbon-doped ternary cobalt-nickel-iron phosphide nanocubes for efficient overall water splitting. Sci China Mater, 2019, 62: 1285-1296

4 Zhang J, Chen Z, Liu C, et al. Hierarchical iridium-based multimetallic alloy with double-core-shell architecture for efficient overall water splitting. Sci China Mater, 2020, 63: 249-257

5 Kumar A, Bhattacharyya S. Porous NiFe-oxide nanocubes as bifunctional electrocatalysts for efficient water-splitting. ACS Appl Mater Interfaces, 2017, 9: 41906-41915

6 Wang L, Wang $\mathrm{X}, \mathrm{Xi} \mathrm{S}$, et al. $\alpha-\mathrm{Ni}(\mathrm{OH})_{2}$ originated from electrooxidation of $\mathrm{NiSe}_{2}$ supported by carbon nanoarray on carbon cloth for efficient water oxidation. Small, 2019, 15: 1902222

7 Song C, Liu Y, Wang Y, et al. Highly efficient oxygen evolution and stable water splitting by coupling NiFe LDH with metal phosphides. Sci China Mater, 2021, 64: 1662-1670

8 Li F, Zhao X, Mahmood J, et al. Macroporous inverse opal-like $\mathrm{Mo}_{x} \mathrm{C}$ with incorporated Mo vacancies for significantly enhanced hydrogen evolution. ACS Nano, 2017, 11: 7527-7533

9 Sun K, Zhao L, Zeng L, et al. Reaction environment self-modification on low-coordination $\mathrm{Ni}^{2+}$ octahedra atomic interface for superior electrocatalytic overall water splitting. Nano Res, 2020, 13: 3068-3074

$10 \mathrm{Wu} \mathrm{H}, \mathrm{Lu} \mathrm{X}$, Zheng G, et al. Topotactic engineering of ultrathin 2D nonlayered nickel selenides for full water electrolysis. Adv Energy Mater, 2018, 8: 1702704

11 Zhu W, Zhang T, Zhang Y, et al. A practical-oriented NiFe-based water-oxidation catalyst enabled by ambient redox and hydrolysis coprecipitation strategy. Appl Catal B-Environ, 2019, 244: 844-852

12 Lu Z, Qian L, Tian Y, et al. Ternary NiFeMn layered double hydroxides as highly-efficient oxygen evolution catalysts. Chem Commun, 2016, 52: 908-911

$13 \mathrm{Xu} \mathrm{H}$, Wang B, Shan C, et al. Ce-doped NiFe-layered double hydroxide ultrathin nanosheets/nanocarbon hierarchical nanocomposite as an efficient oxygen evolution catalyst. ACS Appl Mater Interfaces, 2018, 10: 6336-6345

14 Lim S, Park S, Im S, et al. Chemically deposited amorphous Zn-doped $\mathrm{NiFeO}_{x} \mathrm{H}_{y}$ for enhanced water oxidation. ACS Catal, 2020, 10: 235-244

15 Li R, Wang Y, Li W, et al. Ternary NiFeZr layered double hydroxides: A highly efficient catalyst for the oxygen evolution reaction. Chem Commun, 2019, 55: 13370-13373

16 Zhou D, Cai Z, Lei X, et al. NiCoFe-layered double hydroxides/Ndoped graphene oxide array colloid composite as an efficient bifunctional catalyst for oxygen electrocatalytic reactions. Adv Energy Mater, 2017, 8: 1701905

17 Dinh K, Zheng P, Dai Z, et al. Ultrathin porous $\mathrm{NiFeV}$ ternary layer hydroxide nanosheets as a highly efficient bifunctional electrocatalyst for overall water splitting. Small, 2018, 14: 1703257

18 Liu Y, Bai Y, Han Y, et al. Self-supported hierarchical FeCoNi-LTH/ $\mathrm{NiCo}_{2} \mathrm{O}_{4} / \mathrm{CC}$ electrodes with enhanced bifunctional performance for efficient overall water splitting. ACS Appl Mater Interfaces, 2017, 9: 36917-36926

19 Sun H, Yan Z, Liu F, et al. Self-supported transition-metal-based electrocatalysts for hydrogen and oxygen evolution. Adv Mater, 2020, 32: 1806326

20 Hao S, Chen L, Yu C, et al. NiCoMo hydroxide nanosheet arrays synthesized via chloride corrosion for overall water splitting. ACS Energy Lett, 2019, 4: 952-959 
21 Zhou Q, Hao Q, Li Y, et al. Free-standing trimodal porous NiZn intermetallic and Ni heterojunction as highly efficient hydrogen evolution electrocatalyst in the alkaline electrolyte. Nano Energy, 2021, 89: 106402

22 Liang H, Gandi A, Xia C, et al. Amorphous NiFe-OH/NiFeP electrocatalyst fabricated at low temperature for water oxidation applications. ACS Energy Lett, 2017, 2: 1035-1042

23 Park J, Kim W, Suh C, et al. Catalytic properties of Ni-Zn alloy prepared by mechanical alloying for steam reforming from methanol. Met Mater Int, 2012, 18: 237-241

24 Liu B, Hou J, Zhang T, et al. A three-dimensional multilevel nanoporous $\mathrm{NiCoO}_{2} / \mathrm{Ni}$ hybrid for highly reversible electrochemical energy storage. J Mater Chem A, 2019, 7: 16222-16230

$25 \mathrm{Wu} \mathrm{Z}$, Zou Z, Huang J, et al. $\mathrm{NiFe}_{2} \mathrm{O}_{4}$ nanoparticles/NiFe layered double-hydroxide nanosheet heterostructure array for efficient overall water splitting at large current densities. ACS Appl Mater Interfaces, 2018, 10: 26283-26292

26 Feng Z, Li D, Wang L, et al. In situ grown nanosheet Ni-Zn alloy on $\mathrm{Ni}$ foam for high performance hydrazine electrooxidation. Electrochim Acta, 2019, 304: 275-281

27 Meng $\mathrm{X}$, Han J, Lu L, et al. $\mathrm{Fe}^{2+}$-doped layered double (Ni, $\left.\mathrm{Fe}\right)$ hydroxides as efficient electrocatalysts for water splitting and self-powered electrochemical systems. Small, 2019, 15: 1902551

28 Hu J, Li S, Chu J, et al. Understanding the phase-induced electrocatalytic oxygen evolution reaction activity on $\mathrm{FeOOH}$ nanostructures. ACS Catal, 2019, 9: 10705-10711

29 Ling T, Zhang T, Ge B, et al. Well-dispersed nickel- and zinc-tailored electronic structure of a transition metal oxide for highly active alkaline hydrogen evolution reaction. Adv Mater, 2019, 31: 1807771

30 Liang C, Zou P, Nairan A, et al. Exceptional performance of hierarchical Ni-Fe oxyhydroxide@NiFe alloy nanowire array electrocatalysts for large current density water splitting. Energy Environ Sci, 2020, 13: 86-95

31 Bo $\mathrm{X}$, Li Y, Hocking $\mathrm{R}$, et al. NiFeCr hydroxide holey nanosheet as advanced electrocatalyst for water oxidation. ACS Appl Mater Interfaces, 2017, 9: 41239-41245

32 Luo J, Im J, Mayer M, et al. Water photolysis at $12.3 \%$ efficiency via perovskite photovoltaics and earth-abundant catalysts. Science, 2014, 345: 1593-1596

33 Li Z, Shao M, An H, et al. Fast electrosynthesis of Fe-containing layered double hydroxide arrays toward highly efficient electrocatalytic oxidation reactions. Chem Sci, 2015, 6: 6624-6631

34 Kuai $\mathrm{C}$, Zhang $\mathrm{Y}, \mathrm{Wu} \mathrm{D}$, et al. Fully oxidized Ni-Fe layered double hydroxide with $100 \%$ exposed active sites for catalyzing oxygen evolution reaction. ACS Catal, 2019, 9: 6027-6032

35 Yu L, Yang J, Guan B, et al. Hierarchical hollow nanoprisms based on ultrathin Ni-Fe layered double hydroxide nanosheets with enhanced electrocatalytic activity towards oxygen evolution. Angew Chem Int Ed, 2018, 130: 178-182

36 Zhang Y, Shao Q, Pi Y, et al. A cost-efficient bifunctional ultrathin nanosheets array for electrochemical overall water splitting. Small, 2017, 13: 1700355

37 Jiang J, Sun F, Zhou S, et al. Atomic-level insight into super-efficient electrocatalytic oxygen evolution on iron and vanadium co-doped nickel (oxy)hydroxide. Nat Commun, 2018, 9: 2885

38 Han J, Zhang J, Wang T, et al. Zn doped FeCo layered double hydroxide nanoneedle arrays with partial amorphous phase for efficient oxygen evolution reaction. ACS Sustain Chem Eng, 2019, 7: 1310513114

39 Zhang F, Wang J, Luo J, et al. Extraction of nickel from NiFe-LDH into $\mathrm{Ni}_{2} \mathrm{P} @ \mathrm{NiFe}$ hydroxide as a bifunctional electrocatalyst for efficient overall water splitting. Chem Sci, 2018, 9: 1375-1384

40 Jia Y, Zhang L, Gao G, et al. A heterostructure coupling of exfoliated $\mathrm{Ni}-\mathrm{Fe}$ hydroxide nanosheet and defective graphene as a bifunctional electrocatalyst for overall water splitting. Adv Mater, 2017, 29: 1700017

$41 \mathrm{Yu} \mathrm{L}$, Zhou H, Sun J, et al. Cu nanowires shelled with NiFe layered double hydroxide nanosheets as bifunctional electrocatalysts for overall water splitting. Energy Environ Sci, 2017, 10: 1820-1827

42 Zhang H, Li X, Hähnel A, et al. Bifunctional heterostructure assembly of NiFe LDH nanosheets on NiCoP nanowires for highly efficient and stable overall water splitting. Adv Funct Mater, 2018, 28: 1706847

43 Che Q, Li Q, Tan Y, et al. One-step controllable synthesis of amorphous $(\mathrm{Ni}-\mathrm{Fe}) \mathrm{S} / \mathrm{NiFe}(\mathrm{OH})$ hollow microtube/sphere films as superior bifunctional electrocatalysts for quasi-industrial water splitting at largecurrent-density. Appl Catal B-Environ, 2019, 246: 337-348

44 Yao $\mathrm{M}, \mathrm{Hu} \mathrm{H}$, Sun B, et al. Self-supportive mesoporous $\mathrm{Ni} / \mathrm{Co} / \mathrm{Fe}$ phosphosulfide nanorods derived from novel hydrothermal electrodeposition as a highly efficient electrocatalyst for overall water splitting. Small, 2019, 15: 1905201

45 Yang R, Zhou Y, Xing Y, et al. Synergistic coupling of CoFe-LDH arrays with $\mathrm{NiFe}-\mathrm{LDH}$ nanosheet for highly efficient overall water splitting in alkaline media. Appl Catal B-Environ, 2019, 253: 131-139

$46 \mathrm{Bu} \mathrm{X}$, Wei R, Gao W, et al. A unique sandwich structure of a CoMnP/ $\mathrm{Ni}_{2} \mathrm{P} / \mathrm{NiFe}$ electrocatalyst for highly efficient overall water splitting. J Mater Chem A, 2019, 7: 12325-12332

47 Wang X, Ma W, Ding C, et al. Amorphous multi-elements electrocatalysts with tunable bifunctionality toward overall water splitting. ACS Catal, 2018, 8: 9926-9935

48 Wang $\mathrm{X}, \mathrm{Li} \mathrm{Z}, \mathrm{Wu} \mathrm{D}$, et al. Porous cobalt-nickel hydroxide nanosheets with active cobalt ions for overall water splitting. Small, 2019, 15: 1804832

49 Zhao X, Pachfule P, Li S, et al. Bifunctional electrocatalysts for overall water splitting from an iron/nickel-based bimetallic metal-organic framework/dicyandiamide composite. Angew Chem Int Ed, 2018, 57: 8921-8926

50 Chen J, Pan A, Zhang W, et al. Melamine-assisted synthesis of ultrafine $\mathrm{Mo}_{2} \mathrm{C} / \mathrm{Mo}_{2} \mathrm{~N} @ \mathrm{~N}$-doped carbon nanofibers for enhanced alkaline hydrogen evolution reaction activity. Sci China Mater, 2021, 64: 11501158

51 Cai Z, Bu X, Wang P, et al. Simple and cost effective fabrication of 3D porous core-shell Ni nanochains@NiFe layered double hydroxide nanosheet bifunctional electrocatalysts for overall water splitting. J Mater Chem A, 2019, 7: 21722-21729

Acknowledgements This work was supported by the National Natural Science Foundation of China (51772133), the Natural Science Foundation of Shandong Province (ZR2017JL022), the project of "20 Items of University" of Jinan (2018GXRC001), and the Case-by-Case Project for Top Outstanding Talents of Jinan.

Author contributions Zhou $\mathrm{Q}$ and $\mathrm{Xu} \mathrm{C}$ designed the experiments, collected, and analyzed the data. Zhou Q wrote the manuscript; Xu C revised the manuscript; Liu $\mathrm{H}$ and Yan S provided constructive suggestions. All authors contributed to the general discussion.

Conflict of interest The authors declare that they have no conflict of interest.

Supplementary information Experimental details and supporting data are available in the online version of the paper.

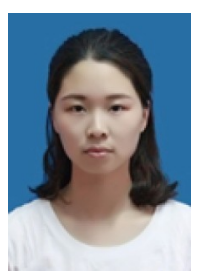

Qiuxia Zhou received her bachelor's and master's degrees from the University of Jinan in 2014 and 2017, respectively. Currently, she is a doctoral student in Prof. Shishen Yan's group at the Spintronics Institute, University of Jinan. Her research focuses on the design and preparation of nanomaterials and their catalytic and electrocatalytic activities, including electrochemical sensing and water splitting. 


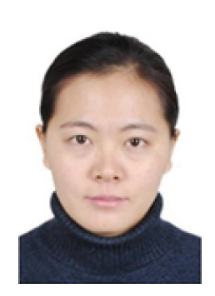

Caixia Xu received her doctoral degree in 2009 from Shandong University. At present, she is a professor at the Institute for Advanced Interdisciplinary Research (iAIR), University of Jinan. Her research focuses on the preparation of nanomaterials and their catalytic and electrocatalytic activities in some small molecules to develop useful advanced materials for fuel cell-related technology, electrochemical sensing, and heterogeneous industrial catalysis.

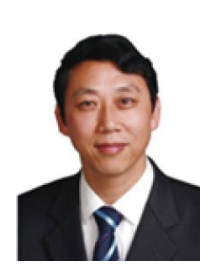

Hong Liu is a professor at the State Key Laboratory of Crystal Materials, Shandong University. He received his doctoral degree in 2001 from Shandong University (China). His current research mainly focuses on the chemical processing of nanomaterials for energy-related applications, including photocatalysis and tissue engineering, especially interactions between stem cells and nanostructures of biomaterials and nonlinear optical crystals.

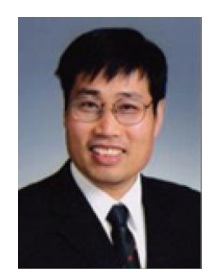

Shishen Yan is a professor at the State Key Laboratory of Crystal Materials, Shandong University. He received his doctoral degree in 1996 from Shandong University (China). His current research focuses on spintronics, including the spin flow generation, transport, regulation and detection, electric field regulation, magnetism, magnetoresistance, rectifier magnetic resistance, spin Hall effect, and spin-orbit coupling.
$\mathrm{NiFeZn-OH}$ 纳米片网络阵列与多层次多孔 $\mathrm{NiZn/Ni}$ 异质结协同耦合实现高效全水分解

周秋霞 ${ }^{1}$, 徐彩霞 ${ }^{*}$, 李雅馨 ${ }^{1}$, 解西沝 ${ }^{1}$, 刘 宏 $^{1,2 *}$, 颜世 申 $^{1^{*}}$

摘要 开发高效、经济的析氧反应(OER)和析氢反应(HER)电催化剂, 在绿色和清洁氢能方面具有广阔的应用前景. 本工作中, 我们在泡沫镍 负载的多层次多孔 $N i Z n$ 金属间化合物 $/ \mathrm{Ni}$ 异质结上原位构筑 $\mathrm{NiFeZn}$ 氢 氧化物纳米片阵列 $(\mathrm{NiFeZn}-\mathrm{OH} / \mathrm{NiZn}-\mathrm{Ni} / \mathrm{NF})$ 用作高效的OER和HER 电催化剂. 首先, 在泡沫镍表面构筑一层双峰多孔 $N i Z n$ 金属间化合物/ $\mathrm{Ni}$, 获得最大程度的催化位点暴露, 然后与 $\mathrm{FeCl}_{3}$ 氧化还原反应生长牢 固的 NiFeZn-OH纳米片阵列. 由于 $\mathrm{Zn}$ 掺杂、多界面工程以及三维一体 化导电骨架的协同效应, NiFeZn-OH/NiZn-Ni/NF对于OER和HER显 示出低的过电势, 在电流密度为 $50 / 600 \mathrm{~m} \mathrm{~A} \mathrm{~cm}^{-2}$ 时分别约为 $235 / 284 \mathrm{mV}$ 和 $73 / 212 \mathrm{mV}$, 其 Tafel斜率分别为 46.1 和 $41.1 \mathrm{mV} \mathrm{dec}^{-1}$, 在 碱性介质中显示出高的催化耐久性. 作为双功能催化剂, NiFeZn-OH/ $\mathrm{NiZn}-\mathrm{Ni} / \mathrm{NF}$ 在全水分解中达到 $20 \mathrm{~mA} \mathrm{~cm}{ }^{-2}$ 仅需 $1.49 \mathrm{~V}\left(100 \mathrm{~mA} \mathrm{~cm}{ }^{-2}\right.$ 时 需 $1.61 \mathrm{~V})$, 且能持续、稳定运行 $40 \mathrm{~h}$. 这项工作有助于探索设计低成 本、高效的金属间化合物/多金属氢氧化物异质结电催化剂, 为其在全 水分解的实际应用提供启示. 